\title{
Sentence context effects on lexically ambiguous words: Evidence for a postaccess inhibition process
}

\author{
SACHIKO KINOSHITA \\ The University of New South Wales, Kensington, New South Wales, Australia
}

\begin{abstract}
Two experiments were conducted to investigate the process involved in selecting the contextually appropriate meaning of a homograph. Both experiments employed a grammaticality decision task. In Experiment 1, the primary (more frequent) and secondary (less frequent) meanings of homographs were used as the target items requiring a "yes" decision. The results indicated that the effect of relative frequency of these meanings of homographs was reduced when the target word was preceded either by a semantically congruous or anomalous sentence context relative to when it was preceded by the grammatical morpheme "the" or "to." Experiment 2 indicated that "no" decisions were consistently slower for syntactically unambiguous, but semantically ambiguous words (e.g., ORGAN, FEET) than for syntactically and semantically unambiguous words (e.g., CENT, LEND), irrespective of the type of preceding context. The results, taken as a whole, are best interpreted within the postaccess inhibition model of sentence-context effects suggested by Forster (1981).
\end{abstract}

In studies of the effects of sentence context on word recognition, typically a response is required to a target word which is preceded by either a semantically congruous sentence context (e.g., "The boy swam under the BRIDGE") or a semantically incongruous sentence context (e.g., "The cook baked the BRIDGE"). Whether the required response is a naming response (i.e., saying the word aloud) or a lexical decision response (i.e., deciding whether the target letter string is a word or a nonsense word), it is found to be faster when the target word is preceded by a congruous context than when it is preceded by an incongruous context (Fischler \& Bloom, 1979, 1980; Forster, 1981; Schuberth \& Eimas, 1977; Schuberth, Spoehr, \& Lane, 1981; Stanovich \& West, 1979, 1981, 1983; West \& Stanovich, 1982).

The majority of explanations proposed for this effect suggest that sentence contexts modify the process of lexical access. With the exception of one interpretation, namely Forster's (1981) postaccess inhibition model, all proposed explanations of sentence-context effects (viz. the two-process model put forward by Posner \& Snyder,

The ideas for the experiments reported in this paper were inspired by an unpublished honors research thesis carried out by Vivien Bainbridge in 1981 under the supervision of Ken Forster at Monash University, Melbourne, Australia. The author gratefully acknowledges the generosity extended by these investigators in allowing her to read the thesis, and, in particular, by Ken Forster for providing insightful comments. Thanks are also due to John Taplin and Marcus Taft for their helpful discussion prior to the preparation of the manuscript, to the editor, Charles Clifton, and to Roger Schvaneveldt and the two anonymous reviewers who provided helpful suggestions for improving on the earlier versions of the paper. Reprint requests should be sent to Sachiko Kinoshita, Department of Psychology, University of New South Wales, P.O. Box 1. Kensington, New South Wales, Australia 2033.
1975; the verification model advanced by Becker, 1980; and the logogen model suggested by Morton, 1969) support the idea that sentence context can be used either in conjunction with, or instead of, the physical (orthographic or phonological) features of the word to locate the entry in the internal lexicon that is semantically congruous with the context.

However, from studies of lexical ambiguity using a cross-modal priming task, there has come a growing body of evidence that lexical access is unaffected by context (e.g., Onifer \& Swinney, 1981; Seidenberg, Tanenhaus, Leiman, \& Bienkowski, 1982; Swinney, 1979; Tanenhaus, Leiman, \& Seidenberg, 1979). In these studies, subjects have been required to listen to a sentence containing lexical ambiguity (e.g., "The postal clerk put the package on a postal SCALE to see if it had enough postage") and simultaneously perform a lexical decision task upon visually presented target letter strings. The results have shown that, when a target item is presented immediately after the occurrence of an ambiguity, words whose meanings are related to either meaning of the ambiguity (e.g., WEIGHT/FISH) are responded to faster than unrelated control words (e.g., SOURCE/COAL), irrespective of the bias of the sentence. This finding has been interpreted as evidence that both contextually appropriate and inappropriate meanings of an ambiguity are momentarily accessed. ${ }^{1}$

The suggestion that contextually inappropriate meaning of a homograph is also accessed is clearly incompatible with the view that sentence contexts guide lexical access to semantically congruous meanings. Instead, this finding is generally taken as evidence that sentence contexts affect only the processes that occur subsequent to lexical access. Specifically, word recognition is assumed 
to involve two processes: an initial lexical access process that is driven solely by the physical features (orthographic or phonological) of the word, and a subsequent identification process that is affected by context (cf. Marcel, 1979, 1983; Onifer \& Swinney, 1981; Seidenberg et al., 1982). Within this view, access alone is not sufficient for a conscious recognition of a word: Such a conscious recognition occurs only when a meaning is identified. The fact that a contextually inappropriate entry is accessed in parallel with a contextually appropriate entry is consistent with the assumption regarding the first stage of word recognition. At the same time, the second assumption suggests that the conscious identification of a word should be affected by sentence context. Support for this latter suggestion can be found in a second result obtained with the cross-modal priming task. The same investigators who obtained evidence of multiple access have also reported that, when a target is presented (usually within $200 \mathrm{msec}$ ) after the occurrence of an ambiguity, only the words that are related to the contextually appropriate meaning of the ambiguity are facilitated relative to the unrelated control words. Taken together with the fact that subjects generally become aware only of the contextually appropriate meaning of a homograph, this finding provides support for the idea that sentence context is used to select the meaning that is made available to consciousness subsequent to lexical access.

Within this interpretation, the measures of sentence contexts found in the naming and lexical decision times may be regarded not merely as being a function of lexical access but also as reflecting the end result of the identification process. Because both naming and lexical decision tasks require an overt response to a target word, they necessarily must involve a conscious identification of the target word. Thus it need not be the case that the sentence context guides lexical access, because it may be argued that the context affects the postaccess identification process. The purpose of the experiments to be reported in this article was to explore the mechanism involved in this process: in particular, how a postaccess process selects the contextually appropriate meaning of a homograph.

If sentence contexts affect the identification process that takes place subsequent to lexical access, then the effect of sentence context may be expected to interact with other factors that are known also to affect the identification of a word. One such factor is the relative frequency of the meaning of a homograph. It has been well established that a more frequent or primary meaning of a homograph is recognized faster than a less frequent or secondary meaning (e.g., Forster \& Bednall, 1976; Hogaboam \& Perfetti, 1975; Holmes, 1979; Simpson, 1981). For example, in an experiment reported by Forster and Bednall (1976, Experiment 2), subjects were presented with a target word preceded by the grammatical morpheme "the" or "to," and were required to decide whether it was a syntactically acceptable usage. Forster and Bednall found that when the target was syntactically ambiguous, the primary meaning (e.g., "the BOX") was responded to more quickly than the secondary meaning (e.g., "to BOX'). Although Forster and Bednall preferred a different interpretation, within the present framework, this finding can be explained as follows. Because the task required the conscious recognition of one of the meanings of the homograph, both the initial access process and the subsequent identification process described above were involved. During access, both meanings of the target homograph were activated in parallel. Following this, one of these meanings had to be consciously chosen as appropriate. In the absence of a semantic context to guide this latter process, it is reasonable to assume that the primary meaning reached the threshold for identification more rapidly than the secondary meaning. Thus, when a decision (in this case, a syntactic acceptability decision) was required for the primary meaning (e.g., "the BOX"), a "yes" decision could be output rapidly. On the other hand, when the decision required the retrieval of the secondary meaning (e.g., "to BOX"), the primary meaning had to be examined first and rejected as syntactically unacceptable before a correct "yes" decision could be output for the secondary meaning. In other words, the effect of relative frequency obtained in Forster and Bednall's experiment may be explained within the present framework in terms of: (1) the difference in time taken for each meaning to reach a threshold (faster for the primary meaning), and (2) the time spent in evaluating and then rejecting the primary meaning when the secondary meaning is relevant.

If, as is suggested here, sentence contexts affect a postaccess identification process, then it may be expected that this context effect will interact with the relative frequency of each meaning of the ambiguous target. One mechanism that may be suggested is that, after multiple meanings of a homograph have been accessed in parallel, the preceding sentence context directs the decision-making mechanism toward the contextually appropriate meaning. This view will be referred to as the access-plus-facilitation view. If this view is correct, then the presence of a congruous sentence context should be of greater benefit to the response for a secondary meaning than to the response for a primary meaning. This is so, because the congruous sentence context will eliminate the time-consuming evaluation of the other (i.e., primary) meaning that occurs when the secondary meaning needs to be identified in the absence of a sentence context (e.g., "to BOX"). Because this time-consuming process does not occur when the primary meaning needs to be identified in the absence of a sentence context (e.g., "the BOX"), the presence of a congruous sentence context will not be of as great a benefit to the primary meaning. According to this account, therefore, it is expected that a smaller effect of relative frequency will be observed in the presence of congruous sentence contexts, relative to the absence of semantic context.

The first experiment to be reported tested this prediction. Subjects were asked to decide whether a given tar- 
get word was a grammatical completion for either a phrase or a sentence. Phrases consisted simply of a grammatical morpheme "the" or "to," followed by a target homograph. Whatever the context, the task required the retrieval of either the primary meaning of a homograph (e.g., "the BOX" or "They all wanted to see what was in the BOX") or the secondary meaning (e.g., "to BOX" or "My brother always wanted to learn to BOX"). It was expected, on the basis of the finding reported by Forster and Bednall (1976), that the primary meaning should be responded to faster than the secondary meaning in the phrase-context condition. In addition, from the above interpretation of sentence-context effects, it was predicted that this effect of relative frequency should be smaller in the sentence-context condition than in the phrase-context condition.

The design of this experiment leaves open the possibility that, in the congruous-sentence-context condition, subjects may respond "yes" or "no" simply on the basis of the meaningfulness of the sentence. For example, when presented with distractor items (for which the required response is "no"), such as "My mother was about to cut the LEND," instead of responding simply to the unacceptable syntax, subjects may respond (correctly) on the basis of the meaninglessness of the sentence as a whole. If this should be the case, then the decision latency would not reflect the time taken to access the appropriate sense of the target and to decide whether or not it belongs to the syntactic category demanded by the sentence context, but instead, it would reflect the time taken to decide whether or not the sentence is meaningful.

In order to discourage subjects from adopting this alternative strategy, a third context condition was introduced. In this condition, the sentence context was always semantically anomalous, and the target was either syntactically acceptable or unacceptable (e.g., "The carpet told me it went to see the BOX"; "Armchairs are a difficult fruit to CENT"'). A decision strategy based solely on meaningfulness of the sentence does not work in this condition. Although it may be argued that subjects could still "switch on" this strategy whenever the context itself was meaningful (i.e., in the congruous-sentencecontext condition), this possibility seems unlikely when the congruous- and anomalous-sentence-context conditions are mixed randomly in the same block of trials (cf. Kiger \& Glass, 1981; Konoshita, Taft \& Taplin, 1985). In any case, the items were chosen to ensure that the level of sentential meaningfulness was equivalent for sentence contexts requiring either the primary meaning or the secondary meaning of a homograph. Thus, any reduction in the effect of relative frequency obtained could not be attributed to any greater meaningfulness for sentences requiring the secondary meaning.

As well as providing better control over subjects' decision strategies, the introduction of an anomaloussentence-context condition allowed the testing of another prediction. According to the present account, a reduction in the effect of relative frequency in the congruoussentence-context condition is predicted on the basis that the context directs the decision-making mechanism toward the meaning that is semantically congruous with it. In the anomalous-sentence-context condition, however, neither the primary meaning nor the secondary meaning of the target homograph is semantically congruous with the context. This means that the decision-making mechanism cannot be guided by the context, and, as in the phrase-context condition, the order of identifying different meanings of a homograph must therefore be determined by relative frequency alone. Thus, there is no reason to expect a reduction in the effect of relative frequency in this third context condition.

In short, the experiment required subjects to make grammatical decisions (i.e., whether or not the target was a syntactically acceptable completion for a given context) in three types of context conditions: phrase contexts (consisting of the grammatical morpheme "the" or "to"); congruous (semantically and syntactically well-formed sentence contexts); and anomalous (semantically anomalous, but syntactically well-formed) sentence contexts. For "yes" decisions, syntactically ambiguous homographs (e.g., BOX) were used as targets, and the context was syntactically biased toward the primary meaning or the secondary meaning. For "no" decisions, semantically and syntactically unambiguous words were used as targets. Examples of contexts and targets are displayed in Table 1.

On the basis of the previous finding by Forster and Bednall (1976), in the phrase condition "yes" decisions are expected to be faster when the primary meaning is relevant (e.g., "the BOX") than when the secondary meaning is required (e.g., "to BOX"). Furthermore, in accordance with the account offered above, that sentence contexts act essentially to facilitate the identification of semantically congruous words, the difference in response times between primary and secondary meanings was predicted to be smaller in the congruous-sentence-context condition, but to remain constant in the anomaloussentence-context condition.

Table 1

Examples of Contexts and Targets Used in Experiment 1

\begin{tabular}{|c|c|c|}
\hline Cond & Context & Target \\
\hline $\begin{array}{l}\text { es Decisi } \\
\text { Primary }\end{array}$ & & \\
\hline $\begin{array}{l}\text { Congruous } \\
\text { Anomalous } \\
\text { Phrase }\end{array}$ & $\begin{array}{l}\text { They all wanted to see what was in the } \\
\text { The carpet told me it went to see the } \\
\text { the }\end{array}$ & $\begin{array}{l}\text { BOX } \\
\text { BOX } \\
\text { BOX }\end{array}$ \\
\hline $\begin{array}{l}\text { Secondary } \\
\text { Congruous } \\
\text { Anomalous } \\
\text { Phrase }\end{array}$ & $\begin{array}{l}\text { My brother always wanted to learn to } \\
\text { The diary was expected to know how to } \\
\text { to }\end{array}$ & $\begin{array}{l}\text { BOX } \\
\text { BOX } \\
\text { BOX }\end{array}$ \\
\hline $\begin{array}{l}\text { Decision } \\
\text { Congruous } \\
\text { Anomalous } \\
\text { Phrase }\end{array}$ & $\begin{array}{l}\text { Chinese is a difficult language to } \\
\text { Armchairs are a difficult fruit to } \\
\text { to }\end{array}$ & $\begin{array}{l}\text { CENT } \\
\text { CENT } \\
\text { CENT }\end{array}$ \\
\hline
\end{tabular}




\section{EXPERIMENT 1}

\section{Method}

Subjects. Thirty-six introductory psychology students at the University of New South Wales participated in the experiment to fulfill course requirements.

Stimuli. Seventy-two noun/verb and verb/noun homographs were used as target items in the "yes" conditions of this experiment. Both systematic and unsystematic homographs were used. Prior to the experiment, a pilot test was carried out to obtain a rating of relative frequency of noun and verb meanings of these words. Eleven subjects, different from those participating in the main experimental task, were presented with a large number of homographs and were asked to rate the relative frequency of noun usage and verb usage of each of the homographs. Of these homographs, only those whose dominant usage was rated as $55 \%$ or above were selected to be used in the experiment (average dominance, 67.1\%). The 72 target items were assigned to the six conditions resulting from the $2 \times 3$ factorial combination of relative frequency (primary and secondary meanings) and context (congruous sentence, anomalous sentence, and phrase). The assignment of the target items was counterbalanced using a Latin square design so that each item was seen by a subject only once and appeared in all six conditions, across subjects. Each subject also saw each sentence context only once.

One-hundred forty-four congruous sentence contexts either were taken from Bloom and Fischler's (1980) pool of items or were generated by the experimenter, with the constraint that the sentences ended in either a noun or a verb. These sentence contexts were then presented to 10 additional introductory psychology students as a Cloze task, and only those words which were produced as sentence completions by $60 \%$ or fewer of the respondents were selected as the actual target items. This selection procedure was to ensure that subjects in the grammaticality decision task could not predict too readily the likely target word, and, thus could not respond solely on the basis of their expectation. Half of these sentences ended with the primary meaning of a homograph, and the other half ended with the secondary meaning. The average Cloze probability for sentences ending with either the primary meaning or the secondary meaning was 0.16 .

The anomalous sentence contexts were generated by changing one or two words of congruous sentence contexts, so that the sentence as a whole was syntactically well formed but semantically anomalous (e.g., "They all wanted to see what was in the BOX" was changed to "The carpet told me it went to see the BOX"). The context in the phrase condition consisted of a grammatical morpheme, either "the" or "to."

In order to ascertain that the sentences for primary/secondary meanings were equally meaningful, the meaningfulness of sentences was rated by 20 additional subjects, who were asked to rate the meaningfulness of the sentences on a scale of 1 to 7 , where 1 was "completely meaningless" and 7 was "highly meaningful." This procedure ensured that interaction between the effects of relative frequency and context was not due to greater facilitation for one level of relative frequency arising from a more meaningful set of sentences. The average rating for congruous sentences was 6.13 for the primary meaning and 5.88 for the secondary meaning. For the anomalous sentences, the average rating was 1.39 for the primary meaning and 1.32 for the secondary meaning.

Procedure. Subjects were told at the beginning of the session that the experiment involved decisions about whether or not a phrase or a sentence was grammatical. The presentation of the phrase condition and the two sentence-context conditions were blocked; half of the subjects did the phrase condition first, and the other half did the sentence-context conditions first. Within the sentence-context block, the congruous and anomalous sentence contexts were mixed randomly. The phrase-context condition was presented in a separate block of trials, because subjects in a pilot experiment involving a mixed presentation complained that it was difficult to deal with the different lengths of phrase and sentence contexts.

In the phrase condition, subjects were told that they would be presented with the word "the" or "to" followed by a noun or a verb inside angle brackets, and that they were to respond "yes" if the word "to" was followed by a verb or if the word "the" was followed by a noun (e.g., "to APPEAR," " the ARMY'), and to respond "no" otherwise. In the two sentence-context conditions, subjects were asked to decide whether the final word of a sentence, presented inside angle brackets, was a grammatical completion for that sentence, irrespective of the plausibility of the sentence.

There were 48 trials in the phrase condition and 96 trials in the sentence-context conditions. Each condition was preceded by 10 practice trials and 2 filler trials of that type.

The stimuli were presented on a video terminal controlled by a Data General D1 16 computer. The items were displayed in a whiteon-black format, all in capital letters. The beginning of each trial was signaled by the words "TRIAL NO." After $500 \mathrm{msec}$ in the phrase condition, either the word "THE" or "TO" was presented immediately below TRIAL NO., and after a 1-sec interval, angle brackets were presented to the right of THE or TO. A target word was presented inside the angle brackets after $100 \mathrm{msec}$ and remained on the screen for $2 \mathrm{sec}$. In the sentence-context conditions, a sentence fragment was presented instead of the words THE or TO, and remained on the screen for $3 \mathrm{sec}$.

Each subject was asked to respond as quickly as possible without sacrificing accuracy. They made the "yes" responses with their preferred hand, and the "no" responses with the nonpreferred hand. Subjects were run either individually or in pairs. Each session lasted approximately $30 \mathrm{~min}$.

\section{Results}

Decision latency for correct responses and the number of errors made were analyzed for each subject's means, treating items as a random variable, and for each item's means, treating subjects as a random variable. ${ }^{2}$ An effect was considered to be significant when it was significant on both subject and item analyses, allowing generalizability to both new subjects and items. All contrasts were fully planned, and the Hays decision rule for establishing the significance of each family was used, holding Type 1 error rate at .05 . Only the "yes" decisions were analysed, using the following factors for planned contrasts: (1) relative frequency (primary and secondary meanings), and (2) context (congruous sentence, anomalous sentence, and phrase). Two types of contrasts were tested for the effect of context: the effect of congruence comparing the phrase condition with the congruous-sentence-context condition, and the effect of semantic anomaly comparing the phrase condition with the anomalous-sentence-context condition. "No" decisions were not analyzed, because the relative frequency factor does not apply to this type of decision. Nevertheless, the decision latency and the error rate data for this decision type are presented in Table 2 along with the "yes" decision data.

For the latency data for "yes" decisions, the main effect of relative frequency was significant $\left[F_{1}(1,35)=\right.$ $21.818, \mathrm{MSe}=7583.288 ; \mathrm{F}_{2}(1,71=15.522, \mathrm{MSe}=$ 27255.455 ], indicating that the primary meaning was responded to faster than the secondary meaning. Deci- 
Table 2

Mean Decision Latencies (in Milliseconds) and Percentage Error Rates (\%E) for "Yes" and "No" Decisions in Experiment 1

\begin{tabular}{|c|c|c|c|c|c|c|}
\hline \multirow{3}{*}{$\begin{array}{l}\text { Decision and } \\
\text { Word Type }\end{array}$} & \multicolumn{6}{|c|}{ Context } \\
\hline & \multicolumn{2}{|c|}{ Congruous } & \multicolumn{2}{|c|}{ Anomalous } & \multicolumn{2}{|c|}{ Phrase } \\
\hline & RT & $\% \mathrm{E}$ & $\mathrm{RT}$ & $\% \mathrm{E}$ & $\mathrm{RT}$ & $\% \mathrm{E}$ \\
\hline \multicolumn{7}{|l|}{ Yes Decision } \\
\hline Primary & 800 & 2.6 & 918 & 11.3 & 904 & 4.6 \\
\hline Secondary & 820 & 5.3 & 947 & 31.3 & 1,044 & 24.8 \\
\hline Difference & 20 & 2.7 & 29 & 20.0 & 140 & 20.2 \\
\hline No Decision & 951 & 9.2 & 982 & 9.7 & 1,167 & 12.6 \\
\hline
\end{tabular}

sions were also made significantly faster in the congruoussentence-context condition than in the phrase condition $\left[\mathrm{F}_{1}(1,35)=47.493, \mathrm{MSe}=13602.383 ; \mathrm{F}_{2}(1,71)=\right.$ $127.829, \mathrm{MSe}=15126.373]$. These effects of relative frequency and congruence, as predicted, produced a significant interaction $\left[\mathrm{F}_{1}(1,35)=25.305, \mathrm{MSe}=\right.$ $2628.299 ; \mathrm{F}_{2}(1,71)=10.453, \mathrm{MSe}=24926.227 \mathrm{l}$, in dicating that the effect of relative frequency was reduced in the congruous sentence context. The effect of semantic anomaly was significant for the items analysis, but not for the subjects analysis $\left[\mathrm{F}_{1}(1,35)=1.707, \mathrm{MSe}=\right.$ $21040.315 ; \mathrm{F}_{2}(1,71)=5.821, \mathrm{MSe}=121625.504 \mathrm{]}$. However, there was a significant interaction between the effects of semantic anomaly and relative frequency $\left[F_{1}(1,35)=14.838, \mathrm{MSe}=5987.247 ; \mathrm{F}_{2}(1,71)=\right.$ 9.143, MSe $=24283.620$ ], indicating again a reduced effect of relative frequency in a sentence-context condition relative to the phrase condition.

The error data generally showed a similar trend. There was a highly significant effect of relative frequency $\left[F_{1}(1,35)=92.350, \mathrm{MSe}=1.716 ; F_{2}(1,71)=67.010\right.$, $\mathrm{MSe}=1.182]$, indicating that more errors were made for the secondary meaning. The main effect of congruence was also significant $\left[\mathrm{F}_{1}(1,35)=61.490, \mathrm{MSe}=.977\right.$; $\left.F_{2}(1,71)=46.638, \mathrm{MSe}=.644\right]$, and the latency data interacted with the effect of relative frequency $\left[\mathrm{F}_{1}(1,35)\right.$ $=39.991, \mathrm{MSe}=.977 ; \mathrm{F}_{2}(1,71)=24.666, \mathrm{MSe}=$ .792]. The main effect of semantic anomaly was significant $\left[F_{1}(1,35)=4.534, \mathrm{MSe}=4.977 ; F_{2}(1,71)=7.090\right.$, $\mathrm{MSe}=1.591]$. It may be noted that this trend was in the direction opposite to that shown by the latency data; that is, while the overall latency for "yes" decisions tended to be faster in the anomalous-sentence-context condition than in the phrase condition, more errors were made in the anomalous context condition. Because the trend for the error data was reversed for "no" decisions (i.e., fewer errors were made in the anomalous-sentence-context condition than in the phrase condition), these effects on errors may be interpreted as due to a response (in)compatibility effect (i.e., a tendency towards responding "no" for semantically anomalous targets). Unlike the latency data, the effects of relative frequency and semantic anomaly on errors did not interact $\left[\mathrm{F}_{1}(1,35)<1.0\right.$; $\left.F_{2}(1,71)<1.0\right]$.

\section{Discussion}

The results of Experiment 1 indicate that, for the error rate data, the pattern of results was consistent with the view that the sentence context facilitates the identification of semantically congruous meanings: The effect of relative frequency was reduced in the congruous-sentencecontext condition, but not in the anomalous-sentencecontext condition. On the other hand, for the latency data, the effect of relative frequency was reduced both in the congruous-sentence-context condition and in the anomalous-sentence-context condition. The first of these two interaction effects was consistent with what was predicted by the access-plus-facilitation model, but because neither the primary nor secondary meaning of target homographs was semantically congruous in the anomalous-sentence-context condition, the second finding was unexpected. It was, therefore, considered necessary to seek an explanation for this latter result.

One possible explanation is that, in both the congruousand anomalous-sentence-context conditions, subjects responded on the basis of sentential meaningfulness rather than on the basis of syntactical acceptability. The fact that decisions were both faster and more accurate in the congruous-sentence-context condition than in the anomalous-sentence-context condition is indeed consistent with this explanation. However, it is difficult to determine how correct decisions were reached at all, following the anomalous sentence contexts, if subjects relied solely on sentential meaningfulness, because these sentences were all intended to be, and were also judged by subjects to be, meaningless. Thus, decision strategy based solely on sentential meaningfulness would have led to an error for each trial in this sentence-context condition. The results indicated, however, that although the error rate was highest in this context condition, nevertheless correct "yes" decisions were reached $78.7 \%$ of the time (averaged over primary and secondary meanings).

It may be argued, alternatively, that subjects responded on the basis of overall sentential meaningfulness only when the sentence context itself was meaningful. Because it would have been possible to distinguish between the congruous and anomalous sentence contexts before a target was presented, subjects may have been able to selectively "switch on" the decision strategy based on the meaningfulness of the sentence as a whole in the congruous sentence-context condition. However, if this had been the case, then the effect of relative frequency should have remained constant across the anomalous-sentence- and the phrase-context conditions in which this strategy could not work. Although the obtained pattern of results for the error rate data is compatible with this explanation, the latency data are not.

A third hypothesis is that subjects may have used the sentence contexts to predict the likely target word, and respond "yes" if the actual target word matched their prediction. It should be pointed out that this explanation 
implies that the context facilitates lexical access of meanings that are congruous with it. Earlier discussion ruled out this possibility on the basis of evidence concerning access of contextually inappropriate meanings of homographs in cross-modal priming studies. It is also unlikely that this strategy was used in the present experiment because the Cloze probability of the congruous sentences was low ( 0.16 for both the primary and secondary senses). In other words, subjects would not have been able to constrain the likely target words sufficiently to facilitate their decisions. It is also difficult to determine how such a strategy would have worked in the anomalous sentencecontext condition, because subjects would not have been able to use the semantic context at all to predict a likely target word.

In summary, putative explanations that view sentence contexts as facilitating decisions on the basis of sentential meaningfulness or predictability cannot account for the pattern of results obtained. However, there is still one other possible explanation of the reduction in the effect of relative frequency on response latencies following both congruous and anomalous contexts. This is the notion that sentence contexts were more effective in resolving syntactical ambiguity than were phrase contexts.

In the present experiment, subjects were shown syntactically ambiguous homographs and were required to decide whether the sense indicated was appropriate for the phrase or sentence contexts used. It is possible that the phrase context consisting of the grammatical morpheme "the" or "to" did not provide a sufficiently strong constraint to indicate the type of syntactical class, and therefore resulted in a large effect of relative frequency. The sentence contexts, on the other hand, may have been more effective in resolving syntactical ambiguity, and therefore reduced the effect of relative frequency. For example, given the sentence contexts "My brother always wanted to learn how to" or "The diary was expected to know how to," it is clear that only a verb could be a syntactically acceptable completion. There are two points at which this resolution of syntactical ambiguity may have occurred. The first possibility is occurrence prior to lexical access; that is, sentence contexts may have been used to constrain the syntactic class of likely target words before the target was presented. This possibility is unlikely because there is evidence (e.g., Oden \& Spira, 1983; Prather \& Swinney, 1977; Seidenberg et al., 1982) that syntactically incompatible meanings of a homograph are accessed in the presence of sentence contexts. The second possible locus of the effect is that the sentence context facilitates the decision-making process after lexical access. How this proposal accounts for the reduced effect of relative frequency in the sentence-context conditions may be described as follows.

Figure 1 represents the phrase-context condition. Let us assume that, in this condition, it takes $s_{1}$ units of time to make a positive decision that a target word may be used as a noun/verb, and $s_{2}$ units to reject an entry as syntactically unacceptable. Following a rejection of an entry, the

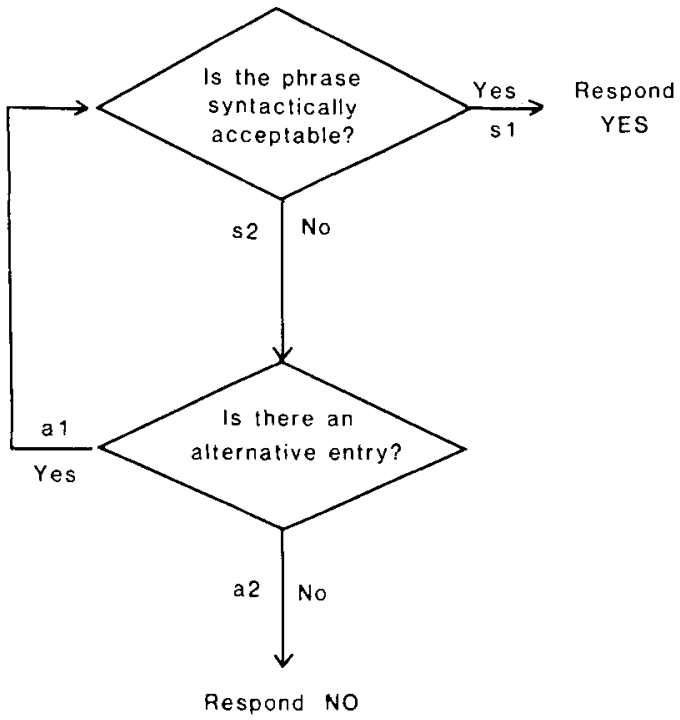

Figure 1. Postaccess decision processes assumed to be involved in the phrase-context condition.

syntactic evaluation process must be repeated for any alternative entries that have been accessed: It is assumed to take $a_{1}$ units to locate an alternative entry, and $a_{2}$ units to find there are no alternative entries. Thus, when a phrase context requires the retrieval of a primary meaning of a homograph (e.g., "the BOX"), it should take $s_{1}$ units to make a "yes" response. On the other hand, when the phrase context requires a secondary meaning (e.g., "to BOX"), the primary meaning must first be evaluated and rejected as syntactically unacceptable (i.e., $s_{2}$ ), then the secondary meaning must be located and found to be syntactically acceptable before a "yes" response may be output. Assuming that these steps occur serially and operate independently of each other, this should result in an effect of relative frequency of the magnitude $\left[\left(s_{2}+a_{1}+s_{1}\right)-s_{1}\right]$ units [i.e., $\left(s_{2}+a_{1}\right)$ units].

Figure 2 depicts the situation in which a syntactic decision is required for a target following a sentence context (congruous or anomalous). In line with the above proposal, the same syntactic decision presumably can be made $\mathrm{x}$ units faster in this condition than in the phrasecontext condition. Thus, in a sentence-context condition, a "yes" response for a primary meaning should take $\left(s_{1}-x\right)$ units to process. In contrast, for a secondary meaning, the response should take $\left[\left(s_{2}-x\right)+a_{1}+\left(s_{1}-x\right)\right]$ units, because the primary meaning must be evaluated before the secondary meaning. This assumption suggests that the effect of relative frequency in a sentence-context condition should be $\left\{\left[\left(s_{2}-x\right)+a_{1}+\left(s_{1}-x\right)\right]-\left(s_{1}-x\right)\right\}$ units, or $\left(s_{2}+a_{1}-x\right)$ units (i.e., $x$ units less than in the phrasecontext condition). Thus, the finding of a smaller effect of relative frequency can be explained if we accept that syntactic acceptability decisions are made more rapidly for targets following a (congruous or anomalous) sentence context. In addition, if it is assumed that the value of $s_{1}$ 


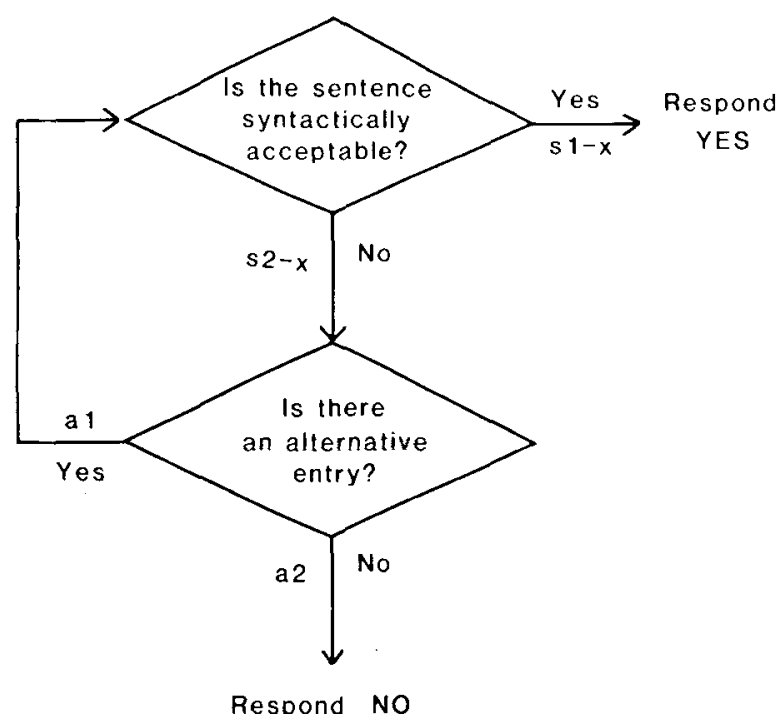

Figure 2. Postaccess decision processes assumed to be involved in the sentence-context conditions within the syntactic-ambiguityresolution account.

is smaller when the sentence as a whole is meaningful as well as syntactically acceptable, then the present account could explain the faster "yes" decisions observed in the congruous-sentence-context condition compared to the anomalous-sentence-context condition. The next experiment was designed to test this explanation.

According to the above view, the entry corresponding to a primary meaning can be rejected as syntactically unacceptable more rapidly following a sentence-context relative to a phrase-context condition. If this is the case, then when two entries belonging to the same target word must be rejected as syntactically unacceptable, the resulting "no" response should also be faster in a sentence-context condition than in a phrase-context condition. Thus, in Experiment 2 , the same grammaticality decision task was employed, using two types of target words that required a "no" decision. One comprised the syntactically and semantically unambiguous words used in Experiment 1 (e.g., CENT, LEND), and the other comprised ambiguous nouns (i.e., nouns which have two or more distinct meanings, e.g., ORGAN, FEET). The same three types of contexts tested in Experiment 1 were again compared. Examples of the "no" decision targets and contexts are

Table 3

Examples of Contexts and Targets Used for "No" Decisions in Experiment 2

\begin{tabular}{|c|c|c|}
\hline Condition & Context & Target \\
\hline $\begin{array}{l}\text { Unambiguous } \\
\text { Congruous } \\
\text { Anomalous } \\
\text { Phrase }\end{array}$ & $\begin{array}{l}\text { Chinese is a difficult language to } \\
\text { Armchairs are a difficult fruit to } \\
\text { to }\end{array}$ & $\begin{array}{l}\text { CENT } \\
\text { CENT } \\
\text { CENT }\end{array}$ \\
\hline $\begin{array}{l}\text { Ambiguous } \\
\text { Congruous } \\
\text { Anomalous } \\
\text { Phrase } \\
\end{array}$ & $\begin{array}{l}\text { My grandmother gave up her will to } \\
\text { The sleepy telephone was eager to } \\
\text { to }\end{array}$ & $\begin{array}{l}\text { FEET } \\
\text { FEET } \\
\text { FEET }\end{array}$ \\
\hline
\end{tabular}

displayed in Table 3. For these stimuli, the following patterns of decision latencies may be expected.

In the phrase-context condition, the ambiguous nouns (e.g., "to FEET") are expected to yield a slower "no" decision than do unambiguous words (e.g. , "to CENT"); this is because two negative decisions, one for each meaning, must be made in the former case, but only one negative decision is required for an unambiguous word. This may be expressed as $\left(s_{2}+a_{2}\right)$ units for an unambiguous word, and $\left(s_{2}+a_{1}+s_{2}+a_{2}\right)$ units for an ambiguous noun using the notation introduced earlier, which results in an effect of ambiguity of magnitude $\left(s_{2}+a_{1}\right)$ units. According to the account described above (which will be referred to as the syntactic-ambiguity-resolution account), a smaller effect of ambiguity is predicted for "no" decisions in the two sentence-context conditions; this is because this view attributes the reduced effect of relative frequency in the two sentence-context conditions obtained in Experiment 1 to a more effective resolution of syntactical ambiguity in the sentence-context conditions relative to the phrase condition. If the amount of this facilitation can be expressed as $x$ units, as has been assumed above, then a "no" decision for an unambiguous word (e.g., CENT) should take $\left[\left(s_{2}-x\right)+a_{2}\right]$ units following a sentence context. On the other hand, a "no" decision for an ambiguous noun (e.g., FEET) should take $\left[\left(s_{2}-x\right)+a_{1}+\left(s_{2}-x\right)+a_{2}\right]$ units. The effect of ambiguity, then, should be $\left(s_{2}+a_{1}-x\right)$ units for targets following a sentence context, that is, $x$ units smaller than that in the phrase-context condition. In other words, according to the syntactic-ambiguity-resolution account, an interaction between the effects of ambiguity and context of the same magnitude as that observed between the effects of relative frequency and context for "yes" decisions should be obtained.

\section{EXPERIMENT 2}

\section{Method}

Subjects. Twenty-four additional subjects from the same population used in Experiment 1 participated in this experiment.

Stimuli. The target words and contexts requiring "yes" decisions were the same as in Experiment 1, except that only half of the sentence contexts were used in Experiment 2: The other half were used as sentence contexts for targets requiring a "no" response. Therefore, for the targets requiring a "yes" response, the effect of relative frequency was assessed as a beiween-items factor. Unlike in Experiment 1, each target was used only once across subjects, either requiring the target's primary or secondary meaning. The assignment of targets to the context conditions was counterbalanced across subjects, so that each target appeared in all three context conditions.

There were also 72 target words that required a "no" response. Half of these were ambiguous nouns, with two or more unrelated meanings (e.g., "ORGAN," "FEET"), and the other half were syntactically and semantically unambiguous words used in Experiment 1 (e.g., "CENT," "LEND"). These two types of words were matched on length (average number of letters per word was 5.0) and frequency of usage [mean frequency was 61.7 per million for ambiguous nouns and 64.3 per million for unambiguous words, ac cording to the Kucera and Francis (1967) norms]. As with the items requiring a "yes" response, each of the target words was assigned to each of the three context conditions, namely, congruous-sentence, 
anomalous-sentence, and phrase conditions. The assignment of target words to the three context conditions was counterbalanced using a Latin square design, so that each subject saw a target word only once, and across subjects, each target appeared in all three context conditions. Examples of contexts and target words are displayed in Table 3. A complete list of the sentence contexts and target words requiring a "no" response is given in Appendix B.

Procedure. The experimental procedure was identical to that employed in Experiment 1.

\section{Results and Discussion}

For Experiment 2, the data for "yes" and "no" decisions were analyzed separately, using the decision latency and error rate measures. As in Experiment 1, for "yes" decisions, the factors were: (1) relative frequency (primary and secondary), and (2) context (congruous sentence, anomalous sentence, and phrase). Two types of contrasts were tested for the effect of context: the effect of semantic congruence, comparing the congruoussentence-context condition with the phrase condition, and the effect of semantic anomaly, comparing the anomaloussentence-context condition with the phrase condition. For "no" decisions, the factors were: (1) ambiguity (ambiguous nouns and unambiguous words), and (2) context (congruous sentence, anomalous sentence, and phrase). As in Experiment 1, all contrasts were fully planned, and the Hays decision rule was used, holding the Type $1 \mathrm{er}-$ ror rate at .05 . The decision latency and error rate data are displayed in Table 4.

For latency data, the same pattern as in Experiment 1 emerged. The main effect of relative frequency was significant $\left[F_{1}(1,23)=50.596, \mathrm{MSe}=11203.473 ; \mathrm{F}_{2}(1,70)\right.$ $=34.188, \mathrm{MSe}=51917.839]$. This effect interacted with the effect of semantic congruence $\left[F_{1}(1,23)=31.051\right.$, $\mathrm{MSe}=2637.149 ; \mathrm{F}_{2}(1,70)=11.383, \mathrm{MSe}=$ 28625.212], indicating a smaller effect of relative frequency in the congruous-sentence-context condition $(85 \mathrm{msec})$ than in the phrase condition $(202 \mathrm{msec})$. The interaction between the effects of relative frequency and semantic anomaly was also significant $\left[F_{1}(1,23)=\right.$ $14.861, \mathrm{MSe}=5158.788 ; \mathrm{F}_{2}(1,70)=4.505, \mathrm{MSe}=$ 33217.478], with the size of the relative frequency effect again reduced in the sentence condition.

For the error data, the effect of relative frequency was also significant $\left[F_{1}(1,23)=83.092\right.$, MSe $=2.166$;

Table 4

Mean Decision Latencies (in Milliseconds) and Percentage Error Rates (\%E) for "Yes" and "No" Decisions in Experiment 2

\begin{tabular}{|c|c|c|c|c|c|c|}
\hline \multirow{3}{*}{$\begin{array}{l}\text { Decision and } \\
\text { Word Type }\end{array}$} & \multicolumn{6}{|c|}{ Context } \\
\hline & \multicolumn{2}{|c|}{ Congruous } & \multicolumn{2}{|c|}{ Anomalous } & \multicolumn{2}{|c|}{ Phrase } \\
\hline & RT & $\% \mathrm{E}$ & RT & $\% \mathrm{E}$ & RT & $\% \mathrm{E}$ \\
\hline \multicolumn{7}{|l|}{ Yes Decision } \\
\hline Primary & 779 & 2.1 & 921 & 4.9 & 837 & 4.9 \\
\hline Secondary & 864 & 9.4 & 1,010 & 27.8 & 1,039 & 30.1 \\
\hline Difference & 85 & 7.3 & 89 & 22.9 & 202 & 25.2 \\
\hline \multicolumn{7}{|l|}{ No Decision } \\
\hline Unambiguous & 996 & 14.9 & 968 & 7.3 & 1,086 & 9.2 \\
\hline Ambiguous & 1,067 & 9.2 & 1,058 & 9.2 & 1,171 & 14.9 \\
\hline Difference & 71 & -5.7 & 90 & 1.9 & 85 & 5.7 \\
\hline
\end{tabular}

$\left.\mathrm{F}_{2}(1,70)=31.991, \mathrm{MSe}=2.877\right]$. As can be seen from Table 4, a larger number of errors was made on the secondary sense $(22.4 \%)$ than on the primary sense $(4.9 \%)$. This effect interacted with the effect of semantic congruence $\left[F_{1}(1,23)=14.794, \mathrm{MSe}=1.878 ; \mathrm{F}_{2}(1,70)=\right.$ $13.802, \mathrm{MSe}=1.413]$. As with the latency data, the effect of relative frequency was reduced in the congruoussentence context $(7.3 \%)$ relative to the phrase condition $(25.2 \%)$. The interaction between the effects of relative frequency and semantic anomaly, however, did not reach statistical significance $\left[\mathrm{F}_{1}(1,23)<1.0 ; \mathrm{F}_{2}(1,70)=3.254\right.$, $\mathrm{MSe}=1.673 \mathrm{]}$.

For "no" decisions, the critical contrasts to be tested were: (1) the effect of ambiguity (ambiguous nouns vs. unambiguous words); (2) the interaction between the effects of ambiguity and semantic congruence; and (3) the interaction between the effects of ambiguity and semantic anomaly. For the latency data, the main effect of ambiguity was significant $\left[\mathrm{F}_{1}(1,23)=16.91\right.$, MSe $=$ $14177.582 ; F_{2}(1,70)=12.976$, MSe $\left.=37396.265\right]$, indicating that, collapsed across all context conditions, the ambiguous nouns were responded to more slowly (by $82 \mathrm{msec}$ ) than were unambiguous words. This effect of ambiguity did not interact with either the effect of semantic congruence $\left[F_{1}(1,23)<1.0 ; F_{2}(1,70)<1.0\right]$ or the effect of semantic anomaly $\left[F_{1}(1,23)<1.0 ; F_{2}(1,70)<\right.$ 1.0]. As can be seen from Table 4, there was a constant effect of ambiguity across the three context conditions.

Unlike the latency data, there was no effect of ambiguity on errors $\left[F_{1}(1,23)<1.0 ; F_{2}(1,70)=2.144\right.$, MSe = 1.816]. The interaction between the effects of ambiguity and semantic congruence, however, was significant on the subjects analysis $\left[\mathrm{F}_{1}(1,23)=12.232, \mathrm{MSe}=0.976\right]$ but not on the items analysis $\left[F_{2}(1,70)<1.0\right]$, indicating that the interaction was not generalizable to new items. The interaction between the effects of ambiguity and semantic anomaly did not reach significance $\left[\mathrm{F}_{1}(1,23)=\right.$ 1.408 , $\left.\mathrm{MSe}=1.065 ; \mathrm{F}_{2}(1,70)<1.0\right]$.

In summary, the "yes" decisions again indicated a reduction of the effect of relative frequency in the two sentence-context conditions relative to the phrase condition. The "no" decisions indicated that ambiguous nouns (e.g., FEET) were responded to equally more slowly than unambiguous words (e.g., CENT) in all three context conditions. This latter finding therefore rules out the possibility that the reduced effect of relative frequency found with the "yes" decisions was due to a more effective resolution of syntactical ambiguity in the sentence-context conditions. If this had been the case, an interaction between the effects of ambiguity and context on "no" decisions should have been obtained of a similar magnitude to that observed between the effects of relative frequency and context observed on "yes" decisions.

\section{GENERAL DISCUSSION}

In both Experiment 1 and Experiment 2, an interaction between the effects of relative frequency and context was found. The results obtained with the latency measure in- 
dicated that, in the phrase condition, decisions were faster when the primary meaning of a homograph had to be retrieved (e.g., "the BOX") than when the secondary meaning had to be retrieved (e.g., "to BOX"), and that this effect of relative frequency was reduced in both congruous- and anomalous-sentence-context conditions. The results of Experiment 2 eliminated the possibility that this interaction was due simply to a more effective resolution of syntactical ambiguity in sentence contexts, as "no" decisions for syntactically unambiguous, but semantically ambiguous, words were equally slower than syntactically and semantically unambiguous words in all three context conditions. Other possible explanations, based on the idea that sentence contexts facilitate lexical access of semantically congruous meanings, or on decision strategies based solely on sentential meaningfulness, were also ruled out by the data.

The initial aim of this paper was to test whether the view that sentence contexts direct the decision-making mechanism toward the semantically congruous meanings can account for the way in which a contextually appropriate meaning of a homograph is identified. On the basis of the findings of the experiments reported here, the answer to this question must be negative. An alternative interpretation of sentence-context effects has been suggested by Forster (1981): This interpretation suggests that the only effect of sentence contexts occurs after lexical access, and that it is inhibitory. In this section, this postaccess inhibition model of sentence-context effects will be described, and the results obtained in Experiments 1 and 2 will be discussed in light of this model.

According to Forster $(1976,1979,1981)$, language processing is assumed to be a linear hierarchy of operations, involving independent subprocesses such as lexical access, syntactic analysis, and semantic processing. Each subprocess is considered to be autonomous, and accepts input only from the next lowest level and no other source. In particular, lexical access is driven solely by the physical features of a word, and is unaffected by previously occurring semantic information. The output of these subprocesses is communicated to the General Problem Solver (GPS), which is responsible for integrating these pieces of information as well as making conscious decisions. While the flow of information is assumed to be strictly serial and bottom-up, Forster suggests that the higher level processes may take less time to complete, and therefore the eventual conscious decision reached may be affected by higher level processing. Thus, for example, an incongruity detected at one level could delay processing at a lower level. Within this framework, the effect of sentence context on word recognition is assumed to have its origin in this postaccess integration stage. Specifically, when the meaning of the accessed entry cannot be meaningfully integrated with the preceding context, instead of proceeding with the processing of that entry at a lower level, its processing is "short-circuited" and a search is initiated to find another entry that is congruous with the context. If no congruous entry can be found, then one of the original entries must be reinstated. In this case, when the target word is preceded by a semantically incongruous context, a slower lexical decision or naming response is obtained relative to when no context is provided. At the same time, this view maintains that a semantically congruous context does not facilitate the response to a given target word, because lexical access itself is assumed not to be guided by context.

How would this model fare in accounting for the results obtained in cross-modal priming studies? First, because the model specifically assumes that lexical access is unaffected by the sentence context, it is consistent with the evidence of multiple accessing of meanings of a homograph presented in context. Second, it is also consistent with the finding that a contextually appropriate meaning is subsequently selected, because the model suggests that, when an accessed entry is found to be semantically incongruous with the context, a search is initiated to find another entry that would make the sentence as a whole meaningful.

How would the postaccess inhibition model account for the latency results in the present experiments? There are three critical findings that need to be explained: (1) the reduced effect of relative frequency in the congruoussentence-context condition, (2) the same reduction observed in the anomalous-sentence-context condition, and (3) the constant effect of ambiguity obtained for "no" decisions across the three context conditions. In accounting for these main findings in terms of the postaccess inhibition model, it is helpful to consider the various processing pathways that may be involved in making the appropriate responses to targets presented following sentence contexts. Figure 3 illustrates these informationprocessing channels proposed by the postaccess inhibition model.

Before examining the model in detail, it should be pointed out that, for the phrase-context condition, the pathways illustrated in Figure la described earlier are assumed still to be involved. Thus, when a "yes" response is required to a primary meaning of a target homograph presented following a grammatical morpheme (e.g., "the BOX'), it should involve the pathway $s_{1}$. On the other hand, when a "yes" 'response is required for a secondary meaning (e.g., "to BOX"), it should involve the pathway $\left(s_{2}+a_{1}+s_{1}\right)$, because the primary meaning must be evaluated and rejected for syntactic unacceptability first, before the secondary meaning can be evaluated. This suggests that an effect of relative frequency of the magnitude $\left(s_{2}+a_{1}\right)$ should be obtained in the phrase-context condition.

Consider now the processes involved in making a response to a target that is preceded by a sentence context. Again, assuming that these steps occur serially and operate independently of each other, in the congruoussentence-context condition, when a "yes" response is required to a primary meaning of a target homograph (e.g., "They all wanted to see what was in the BOX"), this response involves the pathway $m_{1}$ (see Figure 3 ). On the 


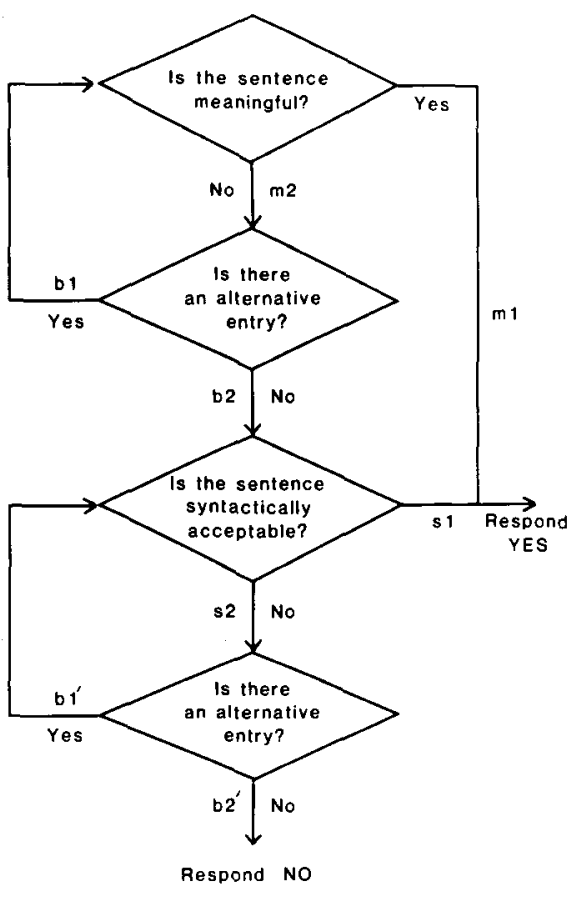

Figure 3. Postaccess decision processes assumed to be involved in the sentence-context conditions within the postaccess inhibition model.

other hand, when a "yes" response is required to a secondary meaning (e.g., "My brother always wanted to learn to BOX"), the pathway involved is $\left(m_{2}+b_{1}+m_{1}\right)$, because the primary meaning must be first evaluated and rejected as being meaningless at the sentential level before the secondary meaning is examined. Thus, the effect of relative frequency should have the magnitude $\left(\mathrm{m}_{2}\right.$ $+b_{1}$ ) units in the congruous-sentence-context condition. It may be recalled at this stage that, according to the postaccess inhibition model, the higher level processes are assumed to be less time-consuming than the lower level processes. This suggests that, when the secondary meaning needs to be identified, the time taken to evaluate and reject the primary meaning should be faster in the congruous-sentence-context condition than in the phrasecontext condition, [i.e., $\left(m_{2}+b_{1}\right)$ must be smaller than $\left.\left(s_{2}+a_{1}\right)\right]$. This leads to the prediction that the effect of relative frequency in the congruous-sentence-context condition should be smaller than that in the phrase-context condition. Thus the postaccess inhibition model correctly predicts the first critical finding.

The second critical finding from the present experiments was that the effect of relative frequency was also reduced in the anomalous-sentence-context condition. In this condition, neither the primary nor secondary meaning was semantically congruous with the context (e.g., "The carpet told me it went to see the BOX"/."The diary was expected to know how to BOX"). According to the model illustrated in Figure 3, for both meanings, the pathway $\left(m_{2}+b_{1}+m_{2}+b_{2}\right)$ must be the one followed. Given this initial rejection of sentential meaningfulness, a deci- sion must be made solely on the basis of the syntactic properties of the entries corresponding to each of these meanings. Forster (1981) proposed that, when the sentence context is semantically incongruous with a target word, following the rejection of all candidate entries, one of the entries is chosen by default; however, he did not specify how this entry is selected. One possibility is that the order in which each entry is examined is no longer determined by frequency of usage. This seems to be a reasonable suggestion, given that the original justification for assuming a frequency-ordered postaccess identification process in the first place was because the primary meaning was assumed to reach the threshold of identification sooner than the secondary meaning. Once all entries have reached the threshold (and have been examined by the semantic processor), however, there seems to be little a priori reason for assuming that subsequent processes will be ordered by frequency. This suggestion would imply that, in some cases, the primary meaning will be examined first by the syntactic processor, and in other cases, the secondary meaning will be examined first. Thus, sometimes a "yes" response to the primary meaning would involve the pathway $\left(m_{2}+b_{1}+m_{2}+b_{2}+\right.$ $\left.s_{1}\right)$, and other times, the pathway $\left(m_{2}+b_{1}+m_{2}+b_{2}\right.$ $+s_{2}+b_{1}{ }^{\prime}+s_{1}$ ). The same pathways would be involved in making a "yes" response to the secondary meaning. This would lead to the prediction that there should be no effect of relative frequency in this context condition. However, in both experiments, there was a residual effect of relative frequency: Responses to the primary meaning were always faster than responses to the secondary meaning. Moreover, the error rate data are incompatible with this interpretation, because the difference in the error rate between the primary and the secondary meanings remained constant across the anomalous-sentencecontext condition and the phrase-context condition.

One way to reconcile these results with the present interpretation is to assume that some of the correct "yes" responses to the primary meaning involved a shorter pathway. Specifically, it may be suggested that, after the primary meaning was rejected on the basis of sentential meaninglessness (i.e., $\mathrm{m}_{2}$ ), the secondary meaning failed to be located $\left(\mathbf{b}_{2}\right)$. It is possible, for example, that subjects have adopted a deadline for terminating the search for an alternative entry such that, if no entry could be found that would make the sentence as a whole meaningful within the deadline, then they proceeded with the next decision process. Following the rejection of the primary meaning on the basis of sentential meaninglessness, the entry is then evaluated for syntactic compatibility with the context $\left(\mathrm{s}_{1}\right)$. When the context demands the primary meaning, the result is a correct, rapid "yes" response. On the other hand, if the context demands the secondary meaning, this pathway results in an incorrect "no" response, because the entry evaluated is syntactically incompatible with this context. Therefore, a greater error rate results for the secondary meaning relative to the primary meaning. In addition, the average latency for correct "yes" responses 
should be faster for the primary meaning than for the secondary meaning. Specifically, let us assume that $P$ represents the proportion of trials involving a shorter pathway (i.e., $m_{2}+b_{2}+s_{1}$ ), and that the rest of the trials were divided equally between $\left(m_{2}+b_{1}+m_{2}+b_{2}+\right.$ $\left.s_{1}\right)$ and $\left(m_{2}+b_{1}+m_{2}+b_{2}+s_{2}+b_{1}{ }^{\prime}+s_{1}\right)$. Thus the average latency for correct "yes" responses for the primary meaning may be expressed as $\left[\mathrm{P}\left(\mathrm{m}_{2}+\mathrm{b}_{2}+\mathrm{s}_{1}\right)\right.$ $+1 / 2(1-P)\left(m_{2}+b_{1}+m_{2}+b_{2}+s_{1}\right)+1 / 2(1-P)\left(m_{2}\right.$ $\left.\left.+b_{1}+m_{2}+b_{2}+s_{2}+b_{1}{ }^{\prime}+s_{1}\right)\right]$, and average latency for the secondary meaning would be $\left[1 / 2\left(m_{2}+b_{1}+m_{2}\right.\right.$ $\left.+b_{2}+s_{1}\right)+1 / 2\left(m_{2}+b_{1}+m_{2}+b_{2}+s_{2}+b_{1}{ }^{\prime}+\right.$ $\left.\left.s_{1}\right)\right]$. The difference between these two expressions, which corresponds to the effect of relative frequency, is $[\mathrm{P} / 2$ $\left.\left(m_{2}+b_{1}\right)+P / 2\left(m_{2}+b_{1}+s_{2}+b_{1}^{\prime}\right)\right]$, or $\left[P\left(m_{2}+\right.\right.$ $\left.\left.b_{1}\right)+P / 2\left(s_{2}+b_{1}{ }^{\prime}\right)\right]$. The value of $P$ can be estimated by the difference in the error rate between the primary and the secondary meanings for the anomalous-sentencecontext condition, which is approximately 0.2 . The estimate of the effect of relative frequency in the anomaloussentence-context condition is therefore approximately $\left\{\left[\left(m_{2}+b_{1}\right) / 5\right]+\left[\left(s_{2}+b_{1}{ }^{\prime}\right) / 10\right]\right\}$. We know that the value of $\left(m_{2}+b_{1}\right)$ is quite small, because this expression corresponds to the size of the effect of relative frequency in the congruous-sentence context. There is also little reason to assume the value of $b_{1}{ }^{\prime}$ to be larger than the value of $a_{1}$. It can therefore be seen that the effect of relative frequency in the anomalous-sentence-context condition is likely to be smaller than $\left(s_{2}+a_{1}\right)$, which is the effect of relative frequency in the phrase-context condition.

Thus, with this additional assumption, the postaccess model also can account for the reduction in the difference in latencies to the primary meaning and the secondary meaning observed in the anomalous-sentence-context condition, the second critical finding reported in this paper. At the same time, the absence of a reduction for the error rate measure can also be accommodated by assuming that the search for an alternative entry was sometimes prematurely terminated by a deadline.

Finally, the effect of ambiguity on "no" decisions obtained in Experiment 2 needs to be explained. Let us first consider the phrase-context condition (see Figure 1). In this condition, a "no" response to an unambiguous word (e.g., "to CENT") is expected to involve the pathway $\left(\mathrm{s}_{2}+\mathrm{a}_{2}\right)$. On the other hand, a "no" response to an ambiguous noun (e.g., "to FEET") should involve the pathway $\left(s_{2}+a_{1}+s_{2}+a_{2}\right)$, because both meanings of FEET must be evaluated and rejected for syntactic unacceptability. This assumption suggests an effect of ambiguity of the magnitude $\left(s_{2}+a_{1}\right)$ units in the phrase-context condition.

Because this estimate of the effect of ambiguity $\left(s_{2}+\right.$ $a_{1}$ ) is the same as that for the effect of relative frequency in the phrase-context condition (also $s_{2}+a_{1}$ ), it may appear that the two effects should be of the same magnitude. This was not the case, because the effect of ambiguity was $85 \mathrm{msec}$ and the effect of relative frequency was $140 \mathrm{msec}$ in Experiment 1 (where the assignment of the target to the two levels of relative frequency-the primary and the secondary meaning-was fully counterbalanced), and $202 \mathrm{msec}$ in Experiment 2 (where the assignment was not counterbalanced across targets). However, this observed value of the effect of ambiguity on "no" responses is likely to be an underestimate, because, just as a correct "yes" response to the primary meaning following an anomalous-sentence context can be made without evaluating the secondary meaning, a correct "no" response to an ambiguous noun can also be made without evaluating two meanings. That is, even if the search for an alternative meaning (that takes place subsequent to the rejection of one meaning) was prematurely terminated by a deadline, and therefore a "no" response was output on the basis of the syntactic unacceptability of the first meaning evaluated, it would have been correct anyway. Thus, some of the correct "no" responses to the ambiguous nouns may have involved the short pathway $\left(s_{2}+a_{2}\right)$, and this may explain why the obtained effect of ambiguity was smaller than the effect of relative frequency. The fact that no main effect of ambiguity was observed for the error-rate measure is also consistent with this account.

Let us now consider the situation in which a "no" response is required to a target word presented following a sentence context (see Figure 3). Irrespective of whether it is a congruous- or anomalous-sentence-context condition, for targets requiring "no" responses, the sentence as a whole would always be meaningless. Thus for an unambiguous word (e.g., "Chinese is a difficult language to CENT"/ "Armchairs are a difficult fruit to CENT"), the pathway $\left(m_{2}+b_{2}+s_{2}+b_{2}{ }^{\prime}\right)$ must be involved. In contrast, for ambiguous nouns (e.g., "My grandmother gave up her will to FEET"/ "The sleepy telephone was eager to FEET' '), the pathway $\left(m_{2}+b_{1}+m_{2}+b_{2}+\right.$ $s_{2}+b_{1}{ }^{\prime}+s_{2}+b_{2}{ }^{\prime}$ ) must be followed, because both entries corresponding to the two meanings of FEET must be evaluated at each level (sentential meaningfulness and syntactic acceptability). If this is the case, then in the sentence-context conditions, the effect of ambiguity on "no" decisions should be of the magnitude $\left(\mathrm{m}_{2}+\mathrm{b}_{1}+\right.$ $\left.s_{2}+b_{1}{ }^{\prime}\right)$. Therefore, the relationship between the effect of ambiguity in the two sentence-context conditions and in the phrase-context condition would depend on the relationship between the values $m_{2}, b_{1}, b_{1}{ }^{\prime}$, and $a_{1}$.

It may be noted that, for the unambiguous words, the observed latency for correct "no" responses in the two sentence-context conditions (average $982 \mathrm{msec}$ ) was approximately $100 \mathrm{msec}$ faster than that in the phrasecontext condition $(1086 \mathrm{msec})$. In other words, $\left(\mathrm{m}_{2}+\mathrm{b}_{2}\right.$ $\left.+s_{2}+b_{2}{ }^{\prime}\right)$ was approximately 100 msec less than $\left(s_{2}\right.$ $+a_{2}$ ). Similarly, the observed latency for correct "no" responses for an ambiguous noun in the two sentencecontext conditions (average $1062.5 \mathrm{msec}$ ) was also approximately $100 \mathrm{msec}$ faster than that in the phrasecontext condition. In other words, $\left(m_{2}+b_{1}+m_{2}+b_{2}\right.$ $+s_{2}+b_{1}{ }^{\prime}+s_{2}+b_{2}{ }^{\prime}$ ) was also approximately $100 \mathrm{msec}$ less than $\left(s_{2}+a_{1}+s_{2}+a_{2}\right)$, perhaps reflecting a bias toward responding "no" when the sentence as a whole 
does not make sense. Given this relationship, then the following equation expanding the ambiguity effect in the sentence context conditions can be derived:

$$
\begin{aligned}
& \left(m_{2}+b_{1}+s_{2}+b_{1}{ }^{\prime}\right) \\
& \quad=\left(m_{2}+b_{1}+m_{2}+b_{2}+s_{2}+b_{1}{ }^{\prime}+s_{2}+b_{2}{ }^{\prime}\right)- \\
& \left(m_{2}+b_{2}+s_{2}+b_{2}{ }^{\prime}\right) \\
& \quad=\left(m_{2}+b_{1}+m_{2}+b_{2}+s_{2}+b_{1}{ }^{\prime}+s_{2}+b_{2}{ }^{\prime}\right)- \\
& {\left[\left(s_{2}+a_{2}\right)-100\right]} \\
& \quad=\left[\left(s_{2}+a_{1}+s_{2}+a_{2}\right)-100\right]-\left[\left(s_{2}+a_{2}\right)-100\right] \\
& \quad=s_{2}+a_{1}
\end{aligned}
$$

Thus, the effect of ambiguity in the sentence-context conditions should be equal to that in the phrase-context condition.

In conclusion, it is argued that, with the additional assumptions indicated, the postaccess inhibition model can provide an account that best fits the results obtained in the two experiments reported here, as well as results that have previously been obtained using a cross-modal priming task. The model suggests that lexical access is unaffected by sentence context, and that the only effect of sentence context is to temporarily suspend further processing of an entry that is semantically incongruous with it. When a homograph is presented in a disambiguating context, the contextually appropriate meaning is selected at the postaccess stage via the inhibition of a contextually inappropriate meaning.

In contrast, it is difficult to explain the obtained findings within the view that sentence contexts facilitate the identification of words whose meanings are semantically congruous. In particular, the reduction in the effect of relative frequency in the case of anomalous-sentence contexts cannot be accommodated without seriously undermining the fundamental tenets of this view.

One final comment is in order. The present interpretation assumes that the postaccess resolution of lexical ambiguity has a semantic basis. Some may wish to argue against this view on the grounds that systematic, as well as unsystematic, homographs were used in the present experiments. Because different entries of a systematic homograph, by definition, are related in meaning (e.g., "to COOK" and "the COOK"), the resolution of this type of ambiguity may be said not to be based on semantic factors.

Against this criticism, however, it should be pointed out that at least two different types of semantic relationship can be distinguished (cf. Forster, 1981; Kleiman, 1980). One type occurs between individual words and involves an associative relationship (e.g., dog-cat, saltpepper) or sharing of semantic features (e.g., nurse-wife, bread-cake). The second type of semantic relationship exists between a sentence context and a word and relies on pragmatics or world knowledge. For example, given the sentence context "The bird flew down on to the," such words as "roof," "lawn," "ground," "perch," "branch," and so forth may come to mind. These words come to mind, not because they are associatively related to any of the individual words in the sentence context, but because they are inferred from what we know in general about the behavior of birds. Furthermore, neither are these words closely associated with each other, nor do they share common semantic features. In other words, the two types of semantic relationship are quite distinct and essentially independent (see Kleiman, 1980, for experimental evidence).

Within the present interpretation, the semantic processing that is assumed to be responsible for the postaccess resolution of lexical ambiguity refers to the second type. In contrast, the semantic relationship that exists between the different entries of a systematic homograph must be of the first type. If this is the case, then there should be no problem in applying the present explanation for the resolution of ambiguity within systematic homographs, as well as unsystematic homographs.

The above view is not meant to deny the role of a semantic relationship that exists between individual words in the resolution of lexical ambiguity. However, as Seidenberg et al. (1982) have remarked, "while many studies of lexical ambiguity have been devoted to a search for evidence that contextual information (provided by individual words) can affect meaning access, the most important context effects may lie elsewhere, at the postaccess decision stage" (p. 529). The postaccess inhibition model discussed in this paper suggests one way in which such a postaccess resolution of lexical ambiguity may be achieved.

\section{REFERENCES}

BeCKER, C. A. (1980). Semantic context effects in visual word recognition: An analysis of semantic strategies. Memory \& Cognition, 8 , 493-512.

Bloom, P. A., \& Fischler, I. (1980). Completion norms for 329 sentence contexts. Memory \& Cognition, 8, 631-642.

Fischler, I., \& Bloom, P. A. (1979). Automatic and attentional processes in the effects of sentence contexts on word recognition. Journal of Verbal Learning \& Verbal Behavior, 18, 1-20.

FischleR, I., \& BLOOM, P. A. (1980). Rapid processing of the meaning of sentences. Memory \& Cognition, 8, 216-225.

Forster, K. I. (1976). Accessing the mental lexicon. In R. J. Wales \& E. Walker (Eds.), New Approaches to Language Mechanisms. Oxford: North-Holland Publishing Co., pp. 257-287.

Forster, K. I. (1979). Levels of processing and the structure of the language processor. In W. E. Cooper \& E. C. T. Walker (Eds.), Sentence Processing: Psycholinguistic Studies. Hillsdale, NJ: Erlbaum.

Forster, K. I. (1981). Priming and the effects of sentence and lexical contexts on naming time: Evidence for autonomous lexical processing. Quarterly Joumal of Experimental Psychology, 33A, 465-496.

Forster, K. I., \& BeDNALl, E. S. (1976). Terminating and exhaustive search in lexical access. Memory \& Cognition, 4, 53-61.

hogaboam, T. W., \& Perfetti, C. A. (1975). Lexical ambiguity and sentence comprehension. Journal of Verbal Learning \& Verbal Behavior, 14, 265-275.

HoLmEs, V. M. (1979). Accessing ambiguous words during sentence comprehension. Quarterly Journal of Experimental Psychology, 31, 569-589.

Kiger, J. I., \& Glass, A. L. (1981). Context effects in sentence verification. Journal of Experimental Psychology: Human Perception \& Performance, 7, 688-700. 
Kinoshita, S., Taft, M, \& Taplin, J. E. (1985). Nonword facilitation effects in a lexical decision task. Journal of Experimental Psychology: Learning, Memory \& Cognition, 11, 346-362.

Kieiman, G. (1980) Sentence frame contexts and lexical decisions: Sentence acceptability and word-relatedness effects. Memory \& Cognition, 8, 336-344.

KUČERA, H., \& Francis, W. (1967). Computational analysis of presentday American English. Providence, RI: Brown University Press.

MarCEL, A. J. (1979). Conscious and preconscious recognition of polysemous words: Locating the selective effects of prior verbal context. In R. S. Nickerson (Ed.), Attention and Performance VIII. Hillsdale NJ: Erlbaum.

MARCEL, A. J. (1983). Conscious and unconscious perception: Experiments on visual masking and word recognition. Cognitive Psychology, 15, 197-237.

MorTon, J. (1969). Interaction of information in word recognition. Psychological Review, 76, 165-178.

ODEN, G. C., \& SPIRA, J. L. (1983). Influence of context on the activation and selection of ambiguous word senses. Quarterly Journal of Experimental Psychology, 35A, 51-64.

ONIFER, W., \& SWINNEY, D. A. (1981). Accessing lexical ambiguities during sentence comprehension: Effects of frequency of meaning and contextual bias. Memory \& Cognition, 9, 225-236.

PosNer, M. I., \& SNyder, C. R. R. (1975). Attention and cognitive control. In R. L. Solso (Ed.), Information Processing and Cognition: The Loyola Symposium. Hillsdale, NJ: Erlbaum.

Prather, P., \& Swinney, D. A. (1977). Some effects of syntactic context upon lexical access. Paper presented at meeting of the American Psychological Association, San Francisco, California.

Schuberth, R. E., \& Eimas, P. D. (1977). Effects of context on the classification of words and nonwords. Journal of Experimental Psychology: Human Perception \& Performance, 3, 27-36.

Schuberth, R. E., Spoetr, K. T., \& Lane, D. M. (1981). Effects of stimulus and contextual information on the lexical decision process. Memory \& Cognition, 9, 68-77.

SeidenberG, M. S., Tanenhaus, M. K., Leiman, J. M., \& BienkowsKI, M. (1982). Automatic access of the meanings of ambiguous words in context: Some limitations of knowledge-based processing. Cognitive Psychology, 14, 489-537.

Simpson, G. B. (1981). Meaning dominance and semantic context in the processing of lexical ambiguity. Journal of Verbal Learning \& Verbal Behavior, 20, 120-136.

Stanovich, K. E., \& West, R. F. (1979). Mechanisms of sentence context effects in reading: Automatic activation and conscious attention. Memory \& Cognition, 7, 77-85.

Stanovich, K. E., \& WEST, R. F. (1981). The effect of sentence context on ongoing word recognition: Tests of two-process theory. Journal of Experimental Psychology: Human Perception \& Performance, 7, 658-672.

Stanovich, K. E., \& WEST, R. F. (1983). On priming by a sentence context. Journal of Experimental Psychology: General, 112, 1-36.

SwinNey, D. A. (1979). Lexical access during sentence comprehension: $(\mathrm{Re})$ consideration of context effects. Journal of Verbal Learning \& Verbal Behavior, 18, 645-659

Tanenhaus, M. K., Leiman, J. M., \& Seidenberg, M. S. (1979). Evidence for multiple stages in the processing of ambiguous words in syntactic contexts. Journal of Verbal Learning \& Verbal Behavior, $18,427-440$.

West, R. F., \& STANOVICH, K. E. (1982). Source of inhibition in experiments on the effect of sentence context on word recognition. Journal of Experimental Psychology: Learning, Memory \& Cognition, 8 , 385-399.

\section{NOTES}

1. Within the lexical ambiguity literature, different views exist regarding the way in which different meanings of a homograph are represented in the mental lexicon. In particular, the different meanings may be represented either as separate entries linked to the same type node (i.e., "satellite" entries) or as separate entries linked to different nodes. It should be pointed out that the discussion presented in this paper is not affected by which of these views of meaning representation is adopted. The only assumption that needs to be made here is that different meanings of a homograph are represented as separate entries.

2. In order to minimize the effect of occasional trials with very long latencies, for each subject the mean latencies over the "yes" and "no" decisions were calculated, and upper and lower cutoffs were set 3 standard deviation units above and below the means for that subject. A similar procedure was carried out for each item collapsed over subjects.

\section{Appendix A}

The items are listed in the order: congruous-sentence context, anomalous-sentence context (separated by $/$ ), followed by the target word (in uppercase letters).

\section{Primary Meaning}

The following items were used in both Experiments 1 and 2 .

They took short trips during the / The zoo had a rich meal during the SPRING

The dry-cleaner had too many trousers to / The computer had many people to PRESS

The artist claimed that nobody taught him how to / The paddock claimed nobody taught him to DRAW

Nobody expected the brave general to / The ocean expected the silent wall to YIELD

The little girl didn't want her dress to / The giant dress didn't want the desk to TEAR

However she tried she could not remove the / However it tried the stairs could not feel the SPOT

She no longer wanted him to / The parcel no longer wanted me to CALL

At the exhibition the children were warned not to / In the kitchen the zebra was asked to TOUCH

One of my great-uncles was a famous / One of my famous ulcers was a JUDGE

The students complained that there wasn't time to / The path argued that there wasn't a thing to FINISH

They said the rain caused the car to / The cliff said the cloud caused the car to SLIP

The young admiral was anxious to / The young wall was eager to SAIL

My father was upset because I mislaid the / The judge was angry because I threw the BOOK

The passengers talked about the memorable / The chairs talked about the terrible TRIP

The grilled sausages were too hot to / The steamed skirt was too hot to HANDLE

They didn't think the plane would / The cigarettes thought the chair would FLY

Nobody expected his new car to / The car expected the delicious vicar to STALL

The champion certainly knew how to / The lazy watch knew how to PUNCH

She said it was her favorite / The peach told him it was a deaf FLOWER

John's new car was difficult to / The purple flour was ready to STEER 


\section{Appendix A (continued)}

My cousin had her holiday pictures to / The oak tree had the potatoes to SHOW

He told the woman behind him not to / The fire told the brave radio not to $\mathrm{PUSH}$

The zebra was too fast for the lion to / The engineer was too tasty for the ant to CHASE

The new product was ready to / The tired season was easy to LAUNCH

She offered the cake for everyone to / The apple pie gave the key for everyone to SHARE

They all wanted to see what was in the / The carpet told him what was in the BOX

In the rain everyone waited for the / The rain waited patiently for the TRAIN

I was waiting for my turn to / The birthday was waiting for its turn to PLAY

The neighbor's cat caused his dog to / The wig ordered the library to BARK

We only had the potatoes left to / The slope still had the apples to SCRUB

It was his mother who taught him to / It was his guitar that taught him to COOK

Her maiden aunt always liked to / The quiet ribbon liked to TRAVEL

The engineers were against the building of the / The soup was against the building of the BRIDGE

The prisoner found the wall too high to / The shirt found the class too large to LEAP

My sister grew up to be a / The handbag grew up to be a NURSE The mechanic said it was difficult to remove the / The cloud said it was dangerous to clean the RUST

The following target words and the sentence contexts were presented in Experiment 1 only.

The security guard was the first to discover the / The orange was the first tool to discover the BOMB

At the zoo children wanted to see the / At the lake the meat wanted to see the BEAR

At the park children wanted to feed the / In the theatre the shelves wanted to throw the DUCK

The escapee couldn't think of anywhere to / The morning couldn't think of anywhere to HIDE

The meat was too large for the dog to / The clock was too bitter for the dog to SWALLOW

She complained that the clothes were too wet to / He said the post office was too tired to IRON

When I buy a book I always look at the / When I buy a cold I always look at its INDEX

They told us the piano was too heavy to / The piano told us it was too hot to MOVE

John poured himself a glass of / The table gave me a bagful of WATER

It was a convenient place for them to / Apples are a dangerous furniture to STOP

The steel tube was difficult to / The colorful door was eager to BEND
It was obvious he didn't appreciate the / It was obvious the garbage hated the COMMENT

Jane could feel the change in the / The chair could tell the loss of the SEASON

The secretary was given the letters to / The desk was given the elephants to POST

All day long he waited for his client to / The ashtray waited for the wall to RING

After a long parade they began to / The forest found it began to TIRE

John had a mouthful of the broth to / The broth poured itself some concrete to TASTE

The potatoes were left on the stove to / The cancer was left on the shelf to BOIL

John was the person he most wanted to / The butter was the person it most wanted to BEAT

The busy executive had no time to / The slow cradle had no time to REST

The mouse expected the cat was ready to / The floor expected the meat was eager to STRIKE

John was eighteen when he started to / The pencil was sweet when it started to SMOKE

Nobody in the audience was going to / The flea in the freezer was going to LAUGH

I thought John was not a very good / The callous leaf was not a very good TUTOR

There were too many people to / There were few silent ribbons to COUNT

For her birthday he gave his mother a / The cruel watch cooked on the RECORD

He always takes a long time deciding what to / The river takes a long time deciding what to WEAR

In the mornings John is impossible to / In summer the precious ground is easy to WAKE

The horses were led into the paddock to / The hospial was led into the bank to GRAZE

The teacher ordered the noisy children not to / The cup ordered the blind lake not to SHOUT

The entire village came to / The moon swam in order to LOOK

The designer told her it was the latest / The glass told him it was a hopeless STYLE

The share prices are continuing to / The tulip expected the earthquake to DROP

John's new horse was difficult to / The vest was too quiet to RIDE

The door was so warped it was impossible to / The apple was so angry it was dangerous to LOCK

She wrote in her letter she had nothing to / The telephone argued that there was something to REGRET

\section{Secondary Meaning}

The following items were used in both Experiments 1 and 2 .

The pilots found the target difficult to / The targets found the broth easy to BOMB

My favorite team's defeat was hard to / The chapel found the event easy to BEAR 
Appendix A (continued)

When shooting started they were ordered to / When the concert started the desks were asked to DUCK

The hunter proudly produced the animal's / The butter proudly produced the deer's HIDE

In spring we look forward to seeing a / In spring the disease looks forward to seeing a SWALLOW

John was able to fix the / The thunder was able to feel the IRON The secretary was given many files to / The fragile road was given vases to INDEX

Only an experienced player could anticipate the / Only the envelope could drink the MOVE

The dust caused his eyes to / The eyes caused the dog to WATER The noisy engine had suddenly come to a / The noisy flowers have come to a STOP

The car slowed down going around the / The vase slowed down going around the BEND

The members of the public were invited to / His new car was invited to COMMENT

Spices were added to the stew to / Cement was added to the stew to SEASON

The truck crashed into the / The salt flew into the POST

She looked into the window and saw a beautiful / The scarf looked into the stove and saw a large RING

John had found that he had no spare / The prison found that it didn't like the TIRE

The homemade beer had a terrible / The factory complained about the gentle TASTE

The chemist provided the ointment to treat the / The pencil provided the curtain to treat the BOIL

The drunken teenagers danced to the / The drunken pen ate the BEAT

The busy executive looked forward to a long / The famous shirt looked forward to a REST

It's impossible to buy bread because of the / It's difficult to eat cancer because of the STRIKE

Even at a distance we could see the / On the loud hill we could see the SMOKE

The act was lousy but the clown got a / The key was young but it got a LAUGH

John had one more class to / The horse had one more news to TUTOR

The princess decided to marry the / The beer did not want to marry the COUNT

His life was so boring there was nothing to / The orange was so patient there was nothing to RECORD

The salesman said the carpet can withstand the / The carpet said he could withstand the WEAR

The widow was not present at the / The books were not happy at the WAKE

The wound almost healed leaving only the / The helmet almost healed leaving only the GRAZE

At the pub he insisted it was his / At the zoo the carpet insisted it was his SHOUT

The man was pleasant but I didn't like his / The plate was clever but I didn't like its LOOK
The hairdresser said her hair was easy to / The floor complained that it was difficult to STYLE

At the edge of the cliff there was a long / At the edge of the apple there was a long DROP

He took me in his new car for a / The factory took the strawberry for a RIDE

Nobody could open the / None of the saucers could eat the LOCK The dying man told his wife his only / The old movie told me its only REGRET

The following targets and the sentence contexts were presented in Experiment 1 only.

The hunter didn't expect the lion to / The wound didn't cause the pot to SPRING

The news was known to the members of the / The shop window went to see the PRESS

The referee announced the game was a / The truck said the wizard was a DRAW

The farmer was pleased with this year's / The parade was angry with last week's YIELD

Jane noticed her new dress had a / The coffee noticed its bag had a TEAR

With her bright red hair she was easy to / The insane red hair was easy to SPOT

He left the message to return the / The message was able to eat the CALL

He was soothed by the gentle / The floor was hurt by the loving TOUCH

They were both so good it was impossible to / The rubbers were so impatient it was easy to JUDGE

The careless stroke almost ruined the / The empty strike went to see the FINISH

At each table I had to fill in another / His new car was drinking a SLIP

For the big yacht race we replaced the / Before the exam the cigarettes bought a SAIL

Nobody knew the phone-number so we were unable to / Savories knew the road but we were unable to BOOK

The small rock on the road caused the girl to / The shrine on the pen caused the news to TRIP

To open the safe he gradually turned the / To close the student the bench turned the HANDLE

He saw the spider finally catch a / The grilled sausages finally broke a FLY

At the market he bought an orange from a / The oranges bought a market from the STALL

Savories were served with the / The pencil was filled with the PUNCH

When spring came roses in the garden began to / During the holiday the snow was expected to FLOWER

The farmer looked for a sign of the disease in the / The disease looked for a sign of the farmer in the STEER

John decided to take Mary to the / The kitchen decided to throw him to the SHOW

What the student needed was a little / What the ceiling expected was a lot of PUSH 


\section{Appendix A (continued)}

We were all exhausted after the / The chairs were pleased with the CHASE

The water police is proud of their new / The wall is eager to drink the LAUNCH

The bank manager advised me not to buy the / The eyes advised me not to drink the SHARE

My brother always wanted to learn to / The diary was expected to know how to BOX

My mother's new dog was impossible to / The dog's new army was easy to TRAIN

The critics said it was his best / The bus said it heard a PLAY

He could tell the type of tree from its / The castle ate its lunch from its BARK

The early settlers spent much time clearing the / The scarf spent much time reading the SCRUB

As a child I always wanted to be a / The lonely dance went to hear a COOK

The writer kept a diary during his / The diary met a writer during the TRAVEL

The river was too wide for the army to / The water was too pretty for them to BRIDGE

His nerves failed before he took the / The nerves were very fond of the LEAP

The little baby was not difficult to / The little lunch was not easy to NURSE

He didn't expect his new knife to / The knife didn't expect the ocean to RUST

\section{Appendix B}

The following items were used for the "no" response condition.

\section{Ambiguous Noun}

My grandmother gave up her will to / The sleepy telephone was eager to FEET

Don't believe everything you / Kill the kettle that you PARTY

We waited for the leading actress to / She waited for the deaf book to VOLUME

None of my friends knew what to / All the spoons learned what to DEGREE

There was one story he wanted to / There was one brick the ear needed to TANK

The singer told her fans she had nothing to / The faithful chair had nothing to PORT

My brother's dream was impossible to / The orange's dream was difficult to DUTY

He didn't expect the neighbors could / He didn't think the flour could DIAMOND

Chinese is a difficult language to / Armchairs are a difficult fruit to PUPIL

She told me weaving is not difficult to / The sofa said cooking is easy to CRANE

This morning he forgot to / Yesterday the carpet forgot to RACKET

By midnight they were expected to / By noon the soup is planning to VICE
The player insisted it was his turn to / The glass insisted it was its turn to COUNTRY

They agreed that the tragic fire was possible to / The window argued that the concert was difficult to BALL

The crowd waited patiently for the game to / The oven waited for the rain to CELL

The man knelt down to / The ashtray knelt down to CHEST It's time for the president to / It's time for the blind garbage to STRAW

The audience began to / The giant measles began to HABIT Young men are being asked to / The cages are being asked to ORGAN

In the heat the butter didn't take long to / In the zoo the street didn't take long to TEMPLE

Without water the flower will / Without headaches the cake will CABINET

He was so shocked he didn't even / The biscuits were so happy they didn't even NUT

The puzzle was not easy to / The sweet ceiling was eager to SAGE

The animals are left free to / The noisy pizzas were left to JUMPER

The army was ready to / The toast was eager to ROOM

They held the coffin ready to / The potatoes held him ready to ARMS

The lion was about to / The lawn was planning to ART

He was interested in how the rats would / The roof was interested in how it would RULER

My mother had the bread ready to / The tired floor was ready to ELEMENT

He found his experience was difficult to / The ceiling found it easy to SHEETS

After a while his thoughts began to / After the game the collar was going to MEAL

John took off his clothes in order to / The cup took off its shoes in order to GLASSES

The hunter didn't expect the lion to / The hungry pot caused the cat to PITCHER

They were both so good that it was impossible to / The pencils were so fast they were impossible to YARN

The small rock on the road caused the girl to / The shrine on the pen caused the news to TURF

When spring came the roses in the garden began to / During the holiday the pencil was expected to BOXER

\section{Unambiguous Noun/Verb}

My brother always wanted to learn to / The diary knew how to FOOD

Nobody knew the telephone number so we couldn't / The scarf knew the road but I couldn't BLOOD

The river was too wide for the army to / The water was too pretty for them to HEALTH

Every month he had to clean his / Every month the pretty calender stole a CREATE

The little baby was not difficult to / The little lunch was eager to MICE 


\section{Appendix B (continued)}

He didn't expect the steel knife to / The knife didn't expect the ocean to ATOM

The old man needed some / The quiet handbag fried some EXIST

The escapee couldn't think of anywhere to / The morning couldn't think of anything to DOCTORS

When he was young he was separated from his / When the brick was young it sat on its MELT

The rider showed off his new / The ink buried its new REACT

He was very happy to see his / The typewriter was going to marry its ASSURE

The boys managed to climb the / The needles managed to peel the WILT

The meat was too large for the dog to / The check was too bitter for the meat to EXAMPLE

She looked back through the open / The computer fell in love with the ADD

She said the clothes were too wet to / The insane hair was easy to RICE

Ample food was made for the / Ample funeral was made for the ALLOW

Jim chose not to join the / The flour decided to join the TEACH

His wife was worried about his / The building was pleased with the EXTEND

He turned on the radio and listened to the / The war turned on the road and heard the DEFINE

They told us the piano was too heavy to / The piano told us it was too sweet to OPERA

The steel tube was impossible to / The careful door was easy to GROCERY
The secretary was given the letters to / The desk was given the elephants to JUG

It was a convenient place for them to / Apples are a dangerous furniture to VEAL

He felt lost in a big / The tumor felt brave in a gentle INVADE The critics said it was his best / The bus said it saw a HEAR He could tell the type of tree from its / The castle ate its lunch from the ASK

The early settlers spent much time clearing the / The scarf spent much time reading the SAVE

For her birthday he gave her a / For its birthday the germs were given a PREPARE

There were too many people for him to / There were too many silent ribbons for him to TRUTH

The designer told her it was the latest / The glass told him it was a hopeless OBTAIN

He always takes a long time deciding what to / The river always takes long deciding what to POET

The students had no idea how to / The garters had no idea how to CITIZEN

John could feel the change in the / The chair could feel the loss of the DESTROY

They left the dirty dishes in the / The pretty cups left him in the QUIT

In the morning he takes a long time to / In summer the lake sings in order to BEER

The farmer was pleased with this year's / The coffee was pleased with his DWELL

(Manuscript received December 19, 1984; revision accepted for publication May 30, 1985.) 